\title{
OPTIMASI REKONFIGURASI JARINGAN DISTRIBUSI RADIAL UNTUK MEMINIMALKAN RUGI JARINGAN MENGGUNAKAN METODE SIMPLE BRANCH EXCHANGE
}

\author{
Yoakim Simamora $^{1}$, Sigit Sukmajati ${ }^{2}$, Rio Afrianda $^{3}$ \\ ${ }^{1}$ yoakim@sttpln.ac.id (Sekolah Tinggi Teknik PLN) \\ ${ }^{2}$ sigitsukmajati@yahoo.com (Sekolah Tinggi Teknik PLN) \\ ${ }^{3}$ rio.sttpln@gmail.com (Sekolah Tinggi Teknik PLN)
}

\begin{abstract}
The increasing electric energy consumption must be balanced with good electricity network quality. To overcome this, we need a distribution network reconfiguration. Reconfiguration in power distribution network is done to improve power distribution network quality. Problem that exist in the radial distribution network is power losses. To minimize the power losses can be overcome by compensating capacitor. Done by determining the location of capacitors in distribution networks. With that the capacitor compensates the distribution network is more effective and efficient in distributing power. In this research discusses the network reconfiguration using simple branch exchange method to reduce power losses in radial distribution networks. Plant that used in this final project is IEEE 33 bus feeders. Simple branch exchange method is a kind of heuristic method. It works by selecting the order of the loop is done for distribution networks reconfiguration. Simulation results show that the use of a simple branch exchange method for reconfiguring network can reduce energy loss by 63,4677 kW. From the simulation results using the distribution system IEEE 33 bus feeders, showed that the decrease of energy losses from 202,6845 $\mathrm{kW}$ become $139,2168 \mathrm{~kW}$.
\end{abstract}

Keywords: Reconfiguration, Power Losses, Simple Branch Exchange

\begin{abstract}
ABSTRAK
Kualita penyaluran energi listrik yang baik sudah menjadi suatu keniscayaan seiring dengan semakin meningkatnya kebutuhan akan energi listrik itu sendiri. Salah satu cara untuk menjawab persoalan tersebut adalah dengan melakukan rekonfigurasi di jaringan distribusi. Rekonfigurasi ini diharapkan mampu memberbaiki kualitas jaringan di sistem distribusi tenaga listrik. Namun adanya rugi-rugi daya yang besar menjadi persoalan yang akan muncul selanjutnya. Untuk menurunkan rugi-rugi daya dapat diatasi dengan mengkompensasi kapasitor. Dilakukan dengan cara penentuan lokasi kapasitor di jaringan distribusi. Sehingga dengan mengkompensasi kapasitor maka jaringan distribusi lebih efektif dan efisien dalam menyalurkan daya. Metoda lain untuk mengatasi rugi - rugi jaringan adalah dengan rekonfihurasi jaringan, dimana menggunakan metode simple branch exchange. Plant yang digunakan pada penelitian kali ini adalah IEEE 33 bus 12,6 kV. Prinsip kerja dari Metode simple branch exchange ini adalah dengan melakukan seleksi urutan loop pada jaringan distribusi sehingga akan membentuk rekonfigurasi jaringan yang baru. Metode rekonfigurasi yang digunakan adalah metode heuristik. Rekonfigurasi jaringan yang diperoleh dari penggunaan penggunaan metode simple branch exchange terbukti mampu membuat rugi-rugi daya menjadi berkurang sebesar 63,4677 kW. Selain itu hasil simulasi dengan menggunakan sistem distribusi IEEE 33 bus 12,6 kV, juga terjadi pengurangan rugirugi daya dari awalnya sebesar 202,6845 kW menjadi 139,2168 kW.
\end{abstract}

Kata kunci: Rekonfigurasi, Rugi-rugi Daya, Simple Branch Exchange 


\section{PENDAHULUAN}

Dalam penyaluran tenaga listrik diperlukan adanya penghubung antara sistem transmisi bertegangan tinggi dengan pengguna listrik. Penghubung tersebut disebut sistem distribusi yang merupakan penghubung antara sistem transmisi bertegangan tinggi dengan pengguna listrik. Sistem distribusi pada umumnya menggunakan tipe konfigurasi radial. Setiap saluran dalam jaringan distribusi memiliki nilai impedansi yang dapat mempengaruhi adanya rugi-rugi daya dan drop tegangan [1]. Hal ini harus diatasi sehingga enegi yang dikirim sama dengan energi yang diterima. Rekonfigurasi jaringan merupakan cara yang efektif dan efisien dalam menurunkan rugi-rugi pada jaringan distribusi.

Sudah banyak metode yang pernah dicoba, tetapi masih banyak kekurangan seperti Metode Newton Rhapson dan fast decoupled kurang cocok digunakan untuk penyelesaian aliran daya pada sistem dirstibusi.Terutama pada jaringan berbentuk radial yang kompleks, diperlukan sebuah metode yang dapat merekonfigurasi jaringan yang mudah serta optimal dalam menurunkan rugirugi energi [1].

Dalam Penelitian ini, menggunakan metode simple branch exchange untuk merekonfigurasi jaringan yang dilakukan dengan cara menambahkan switch dengan mengubah on atau off saluran dan pencarian konfigurasi yang menghasilkan rugi-rugi daya terkecil, serta menghitung rugi-rugi daya berdasarkan beban jaringan.

\section{METODE PENELITIAN}

Pada penelitian ini digunakan metode simple branch exchange untuk mendapatkan rekonfigurasi jaringan yang paling optimal.

Pada sistem distribusi seringkali terjadi beban yang tidak seimbang pada setiap fasanya (sistem distribusi merupakan sistem tiga fasa) atau terjadi kelebihan beban karena pemakaian alatalat elektronik dari konsumen energi listrik. Keadaan tersebut jika dibiarkan terus-menerus maka akan menyebabkan terjadinya penurunan keandalan sistem tenaga listrik dan kualitas energi listrik yang disalurkan serta menyebabkan kerusakan alat-alat yang bersangkutan. Untuk itu diperlukan suatu tindakan yang mengurangi pembebanan yang tidak seimbang (unbalanced loading) pada fasa dan kelebihan beban (over loading) pada jaringan distribusi listrik. Selain itu, sistem distribusi radial juga mempunyai rugi - rugi daya yang cukup besar sehingga menyebabkan keandalan sistem menjadi berkurang [2].

Dalam kondisi operasi normal, rekonfigurasi jaringan dilakukan karena dua alasan:

1. Mengurangi rugi-rugi daya pada sistem (loss reduction).

2. Mendapatkan pembebanan yang seimbang untuk mencegah pembebanan yang berlebih pada jaringan (load balancing) [3].

\subsection{Metode Simple Branch Exchange}

Rekonfigurasi pada penelitian ini menggunakan metode simple branch exchange . Metode ini merupakan jenis dari metode heuristic. Rekonfigurasi dilakukan dengan mengubah on atau off switch dan saluran pada setiap konfigurasi sistem daya yang mungkin untuk mendapatkan rugirugi daya yang terkecil. Metode ini merupakan dasar untuk menentukan rugi-rugi daya. Rumus untuk meminimalkan rugi-rugi daya adalah sebagai berikut [4]

$$
P_{\text {loss }}=\sum r_{i} \frac{P_{i}^{2}+Q_{i}{ }^{2}}{V_{i}{ }^{2}}
$$


Metode ini bertujuan untuk mendapatkan konfigurasi jaringan yang baru berdasarkan rugi-rugi daya yang terkecil. Oleh karena itu kelebihan dari branch exchange untuk mencari solusi optimal cabang untuk menurunkan rugi-rugi daya. Metode ini hanya digunakan pada sistem distribusi dengan topologi jaringan radial. Berikut adalah gambar dari struktur sistem sistem radial :

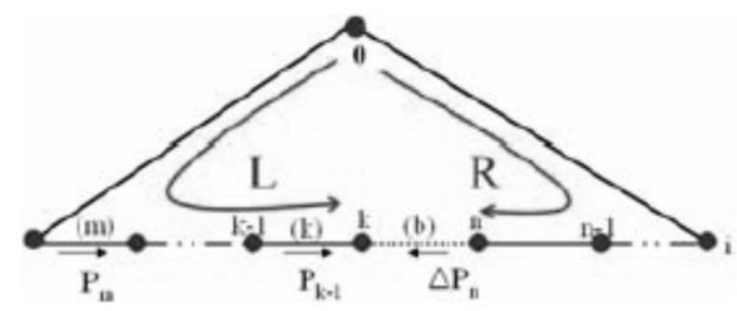

Gambar 1. Sistem Distribusi Radial

Dari gambar di atas dapat diketahui bahwa jika sectionalized switch $\mathrm{b}=$ closed, maka jaringan tersebut akan terjadi loop. Hal ini bertentangan dengan struktur sistem distribusi radial. Maka tiap sectionalized switch di sisi 1 atau $\mathrm{r}$ harus dibuka agar tidak terbentuk loop pada jaringan.

\subsection{Data Penelitian}

Penelitian ini menggunakan jaring radial 33-bus, dengan tegangan 12,66 kV [5]. -Data-data jaring dan beban pada setiap bus terdapat pada Tabel 1 dan Tabel 2. Jaringan yang disimulasikan menggunakan jaring radial 33-bus, Dalam sistem ini terdapat 37 saklar yang terdiri dari 5 tie-lines (normally open) dan 32 saklar pemisah (normally close). 5 tie-lines terdapat pada saluran 33 sampai dengan saluan 37 dan 32 saklar pemisah terdapat pada saluran 1 sampai dengan saluran 32 . Data-data saluran dan beban diambil dari dengan total daya aktif dari beban adalah $3715 \mathrm{~kW}$ serta total daya reaktif dari beban sebesar $2300 \mathrm{kVAR}$. Kerugian daya yang didapatkan dari sistem distribusi sebelum rekonfigurasi sebesar $201,6845 \mathrm{~kW}$ dan magnitudo tegangan yang paling rendah terdapat di bus 18 dengan nilai 0,9131 p.u. Data-data jaring dan beban pada setiap bus terdapat pada Tabel 1 dan Tabel 2.

Tabel 1. Data Saluran

\begin{tabular}{|l|l|l|l|l|}
\hline \multirow{2}{*}{$\begin{array}{l}\text { Nomor } \\
\text { Saluran }\end{array}$} & \multicolumn{3}{|l|}{ Saluran } & \multicolumn{2}{l|}{ Impedansi } \\
\cline { 2 - 5 } & Dari & Ke & R $($ Ohm $)$ & X $($ Ohm $)$ \\
\hline 1 & 1 & 2 & 0,0922 & 0,0470 \\
\hline 2 & 2 & 3 & 0,4930 & 0,2511 \\
\hline 3 & 3 & 4 & 0,3660 & 0,1864 \\
\hline 4 & 4 & 5 & 0,3811 & 0,1941 \\
\hline 5 & 5 & 6 & 0,8190 & 0,7070 \\
\hline 6 & 6 & 7 & 0,1872 & 0,6188 \\
\hline 7 & 7 & 8 & 0,7144 & 0,2351 \\
\hline 8 & 8 & 9 & 1,0300 & 0,7400 \\
\hline 9 & 9 & 10 & 1,0440 & 0,7400 \\
\hline 10 & 10 & 11 & 0,1966 & 0,0650 \\
\hline 11 & 11 & 12 & 0,3744 & 0,1238 \\
\hline 12 & 12 & 13 & 1,4680 & 1,1550 \\
\hline
\end{tabular}




\begin{tabular}{|c|c|c|c|c|}
\hline \multirow{2}{*}{$\begin{array}{l}\text { Nomor } \\
\text { Saluran }\end{array}$} & \multicolumn{2}{|c|}{ Saluran } & \multicolumn{2}{|c|}{ Impedansi } \\
\hline & Dari & $\mathrm{Ke}$ & $\mathbf{R}(\mathbf{O h m})$ & $\bar{X}$ (Ohm) \\
\hline 13 & 13 & 14 & 0,5416 & 0,7129 \\
\hline 14 & 14 & 15 & 0,5910 & 0,5260 \\
\hline 15 & 15 & 16 & 0,7463 & 0,5450 \\
\hline 16 & 16 & 17 & 1,2890 & 1,7210 \\
\hline 17 & 17 & 18 & 0,7320 & 0,5740 \\
\hline 18 & 2 & 19 & 0,1640 & 0,1565 \\
\hline 19 & 19 & 20 & 1,5042 & 1,3554 \\
\hline 20 & 20 & 21 & 0,4095 & 0,4784 \\
\hline 21 & 21 & 22 & 0,7089 & 0,9373 \\
\hline 22 & 3 & 23 & 0,4512 & 0,3083 \\
\hline 23 & 23 & 24 & 0,8980 & 0,7091 \\
\hline 24 & 24 & 25 & 0,8960 & 0,7011 \\
\hline 25 & 6 & 26 & 0,2030 & 0,1034 \\
\hline 26 & 26 & 27 & 0,2842 & 0,1447 \\
\hline 27 & 27 & 28 & 1,0590 & 0,9337 \\
\hline 28 & 28 & 29 & 0,8042 & 0,7006 \\
\hline 29 & 29 & 30 & 0,5075 & 0,2585 \\
\hline 30 & 30 & 31 & 0,9744 & 0,9630 \\
\hline 31 & 31 & 32 & 0,3105 & 0,3619 \\
\hline 32 & 32 & 33 & 0,3410 & 0,5302 \\
\hline 33 & 8 & 21 & 2,0000 & 2,0000 \\
\hline 34 & 9 & 15 & 2,0000 & 2,0000 \\
\hline 35 & 12 & 22 & 2,0000 & 2,0000 \\
\hline 36 & 18 & 33 & 0,5000 & 0,5000 \\
\hline 37 & 25 & 29 & 0,5000 & 0,5000 \\
\hline
\end{tabular}

Tabel 2. Data Beban

\begin{tabular}{|c|c|c|}
\hline \multirow{2}{*}{ No. bus } & \multicolumn{2}{|c|}{ Beban } \\
\hline & $\mathbf{P}(\mathbf{k W})$ & Q (kVAR) \\
\hline 2 & 100 & 60 \\
\hline 3 & 90 & 40 \\
\hline 4 & 120 & 80 \\
\hline 5 & 60 & 30 \\
\hline 6 & 60 & 20 \\
\hline 7 & 200 & 100 \\
\hline 8 & 200 & 100 \\
\hline 9 & 60 & 20 \\
\hline 10 & 60 & 20 \\
\hline 11 & 45 & 30 \\
\hline 12 & 60 & 35 \\
\hline 13 & 60 & 35 \\
\hline 14 & 120 & 80 \\
\hline 15 & 60 & 10 \\
\hline
\end{tabular}




\begin{tabular}{|c|c|c|}
\hline \multirow{2}{*}{ No. bus } & \multicolumn{2}{|c|}{ Beban } \\
\hline & $\mathbf{P}(\mathbf{k W})$ & Q (kVAR) \\
\hline 16 & 60 & 20 \\
\hline 17 & 60 & 20 \\
\hline 18 & 90 & 40 \\
\hline 19 & 90 & 40 \\
\hline 20 & 90 & 40 \\
\hline 21 & 90 & 40 \\
\hline 22 & 90 & 40 \\
\hline 23 & 90 & 50 \\
\hline 24 & 420 & 200 \\
\hline 25 & 420 & 200 \\
\hline 26 & 60 & 25 \\
\hline 27 & 60 & 25 \\
\hline 28 & 60 & 20 \\
\hline 29 & 120 & 70 \\
\hline 30 & 200 & 600 \\
\hline 31 & 150 & 70 \\
\hline 32 & 210 & 100 \\
\hline 33 & 60 & 40 \\
\hline Jumlah & 3715 & 2300 \\
\hline
\end{tabular}

\section{HASIL DAN PEMBAHASAN}

Kondisi eksisting jaringan sebelum dilakukan rekonfigurasi jaringan seperti terlihat pada gambar 2 yang ditunjukkan dibawah. Tegangan yang digunakan pada sistem ini adalah $12,66 \mathrm{kV}$, dengan 37 saluran. Sistem yang digunakan pada penelitian ini adalah sistem IEEE 33-bus dengan 37 saluran yang terdiri dari 32 saklar pemisah (normally close) dan 5 saluran tie-lines (normally open) seperti terlihat pada gambar 2, 5 tie-lines terdapat pada saluran 33 sampai dengan saluan 37 dan 32 saklar pemisah terdapat pada saluran 1 sampai dengan saluran 32. Setiap saluran (kabel) pada sistem memiliki saklar pemisah berupa Circuit Breaker untuk keperluan rekonfigurasi. Tegangan yang digunakan pada sistem ini adalah $12,66 \mathrm{kV}$. Data saluran dan beban pada setiap bus terdapat pada Tabel 1 dan Tabel 2 dengan total daya aktif dari beban adalah $3715 \mathrm{~kW}$ dan total daya reaktif dari beban adalah $2300 \mathrm{kVAR}$ 


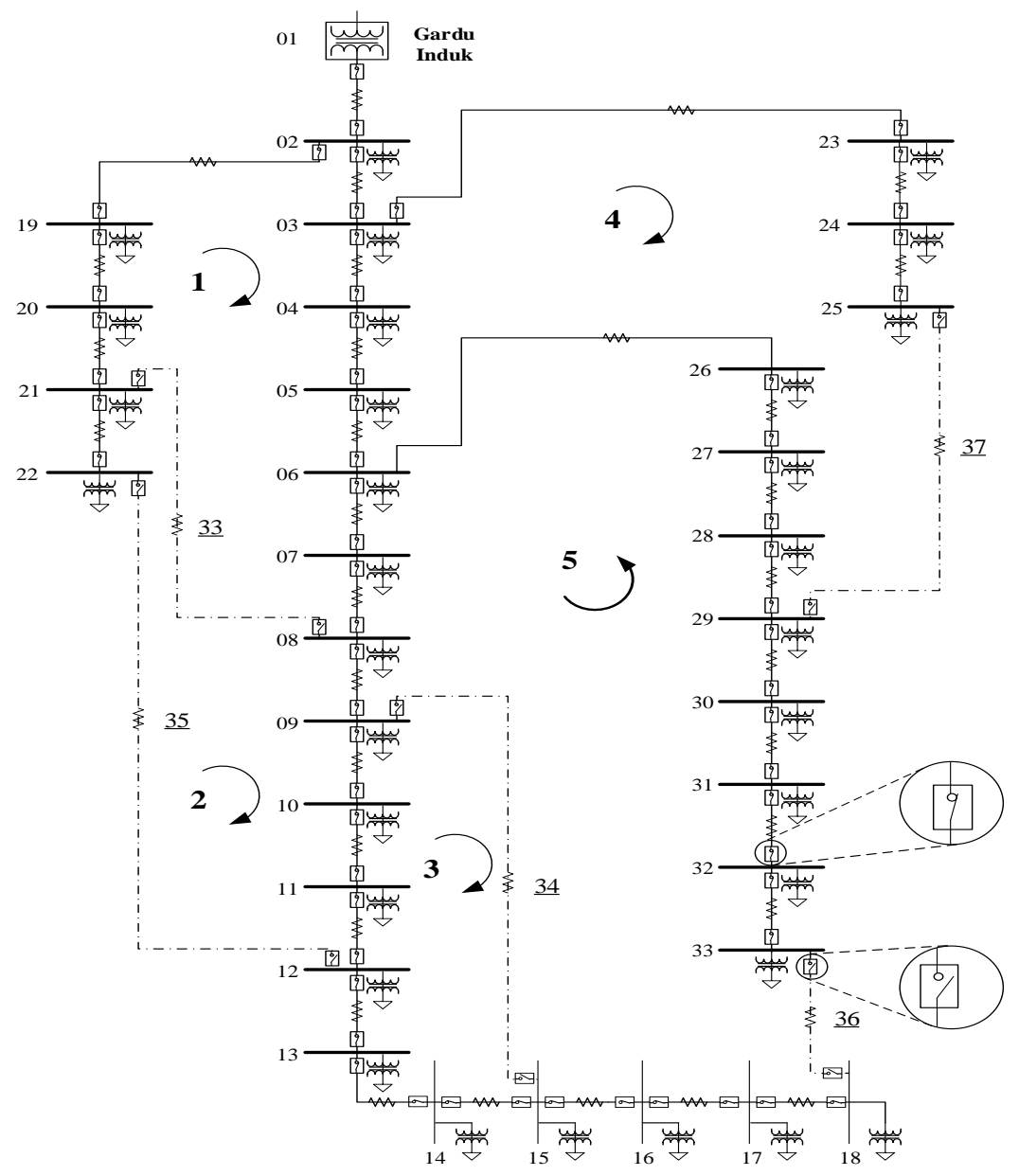

Gambar 2. Single Line Diagram Jaring Distribusi 33-Bus Sebelum Rekonfigurasi

\subsection{Hasil Simulasi Sistem Radial 33-Bus Sebelum Rekonfigurasi}

Tahap ini dilakukan analisis aliran daya menggunakan metode BIBC-BCBV dengan sistem radial pada kondisi sebelum rekonfigurasi. Pada kondisi ini, saluran tie-switch dengan status normally open adalah 33, 34, 35, 36, 37. Hasil simulasi aliran dayan yang meliputi perhitungan dan algoritma dari sistem 33-bus pada saat sebelum dilakukan rekonfigurasi bisa disajikan dalam tabel.3 seperti terlihat pada tabel 3

Tabel 3. Tegangan Sistem 33-Bus Sebelum Rekonfigurasi

\begin{tabular}{|l|l|l|l|l|}
\hline \multirow{2}{*}{$\begin{array}{l}\text { No. } \\
\text { bus }\end{array}$} & \multicolumn{2}{|c|}{ Matlab } & \multicolumn{2}{c|}{ ETAP } \\
\cline { 2 - 5 } & Tegangan (p.u) & Angle (derajat) & Tegangan (p.u) & Angle (derajat) \\
\hline 1 & 1 & 0 & 1 & 0 \\
\hline 2 & 0,997 & 0,0145 & 0,997 & 0,01 \\
\hline 3 & 0,9829 & 0,096 & 0,9829 & 0,1 \\
\hline 4 & 0,9755 & 0,1617 & 0,9755 & 0,16 \\
\hline 5 & 0,9681 & 0,2283 & 0,9681 & 0,23 \\
\hline 6 & 0,9497 & 0,1338 & 0,9497 & 0,13 \\
\hline 7 & 0,9462 & $-0,0965$ & 0,9462 & $-0,1$ \\
\hline
\end{tabular}




\begin{tabular}{|c|c|c|c|c|}
\hline \multirow{2}{*}{$\begin{array}{l}\text { No. } \\
\text { bus }\end{array}$} & \multicolumn{2}{|c|}{ Matlab } & \multicolumn{2}{|c|}{ ETAP } \\
\hline & Tegangan (p.u) & Angle (derajat) & Tegangan (p.u) & Angle (derajat) \\
\hline 8 & 0,9413 & $-0,0599$ & 0,9413 & $-0,06$ \\
\hline 9 & 0,935 & $-0,133$ & 0,935 & $-0,13$ \\
\hline 10 & 0,9292 & $-0,196$ & 0,9292 & $-0,2$ \\
\hline 11 & 0,9284 & $-0,1887$ & 0,9284 & $-0,19$ \\
\hline 12 & 0,9269 & $-0,1773$ & 0,9269 & $-0,18$ \\
\hline 13 & 0,9208 & $-0,2686$ & 0,9208 & $-0,27$ \\
\hline 14 & 0,9185 & $-0,3472$ & 0,9185 & $-0,35$ \\
\hline 15 & 0,9171 & $-0,3849$ & 0,9171 & $-0,38$ \\
\hline 16 & 0,9157 & $-0,4082$ & 0,9157 & $-0,41$ \\
\hline 17 & 0,9137 & $-0,4855$ & 0,9137 & $-0,48$ \\
\hline 18 & 0,9131 & $-0,495$ & 0,9131 & $-0,49$ \\
\hline 19 & 0,9965 & 0,0037 & 0,9965 & 0 \\
\hline 20 & 0,9929 & $-0,0633$ & 0,9929 & $-0,06$ \\
\hline 21 & 0,9922 & $-0,0827$ & 0,9922 & $-0,08$ \\
\hline 22 & 0,9916 & $-0,103$ & 0,9916 & $-0,1$ \\
\hline 23 & 0,9794 & 0,0651 & 0,9794 & 0,07 \\
\hline 24 & 0,9727 & $-0,0237$ & 0,9727 & $-0,02$ \\
\hline 25 & 0,9694 & $-0,0674$ & 0,9694 & $-0,07$ \\
\hline 26 & 0,9477 & 0,1733 & 0,9477 & 0,17 \\
\hline 27 & 0,9452 & 0,2295 & 0,9452 & 0,23 \\
\hline 28 & 0,9337 & 0,3124 & 0,9337 & 0,31 \\
\hline 29 & 0,9255 & 0,3903 & 0,9255 & 0,39 \\
\hline 30 & 0,9219 & 0,4956 & 0,9219 & 0,5 \\
\hline 31 & 0,9178 & 0,4112 & 0,9178 & 0,41 \\
\hline 32 & 0,9169 & 0,3881 & 0,9169 & 0,39 \\
\hline 33 & 0,9166 & 0,3804 & 0,9166 & 0,38 \\
\hline
\end{tabular}

Dari hasil simulasi dengan ETAP didapatkan total kerugian daya aktif sebesar $203 \mathrm{~kW}$ dan total kerugian daya reaktif sebesar $135 \mathrm{kVAR}$. Secara keseluruhan sebelum dilakukan rekonfigurasi jaringan tegangan rata - rata nya adalah 0,95 . Tabel 3 menunjukkan ada 21 bus yang mempunyai tegangan berada di bawah standar minimum ( 0,95 p.u.) yakni bus 6 sampai 18 dan bus 26 sampai 33. Kondisi tersebut menggambarkan bahwasanya pada bus - bus tersebut terjadi under voltage yang berakibat terjadinya penurunan kualitas pelayanan listrik yang akan diberikan kepada kosumen. Dari hasil analisis aliran daya sistem 33-bus pada kondisi sebelum rekonfigurasi didapatkan total kerugian daya aktif sebesar $202,6845 \mathrm{~kW}$ dan total kerugian daya reaktif sebesar 135,1414 kVAR serta tegangan minimum terjadi di bus-18 sebesar 0,9131 per unit

Total daya aktif beban ditambah kerugian daya aktif sebesar 3,9177 MW dan total daya reaktif beban dan kerugian daya reaktif sebesar 2,4351 MVAR dari hasil analisis aliran daya sistem 33-bus sebelum rekonfigurasi. Dari hasil ETAP didapatkan total daya aktif beban dan kerugian daya aktif sebesar 3,918 MW dan total daya reaktif beban dan kerugian daya reaktif sebesar 2,435 MVAR. 


\subsection{Hasil Simulasi Sistem Radial 33-Bus Setelah Rekonfigurasi Menggunakan Metode Simple Branch Exchange}

Tahap ini dilakukan penataan ulang saluran penghubung antar tiap bus yang terdapat pada penyulang sehingga penataan ulang saluran bisa mendapatkan profil tegangan yang lebih baik, kerugian daya yang minimal. Pada sistem radial 33-bus setelah rekonfigurasi analisis aliran daya juga menggunakan metode BIBC-BCBV. Setelah rekonfigurasi saluran tie-switch dengan status normally open adalah 37 dan saluran tie-switch dengan status normally close adalah 33, 34, 35, 36 dan saklar pemisah dengan status normally open adalah 7, 9, 14, 32. Untuk detail jaring distribusi setelah dilakukan rekonfigurasi dapat dilihat pada Gambar 3. Semua Hasil simulasi dan perhitungan algoritma dari aliran daya pada sistem 33-bus saat kondisi setelah dilakukan rekonfigurasi jaringan disajikan pada Tabel 4.

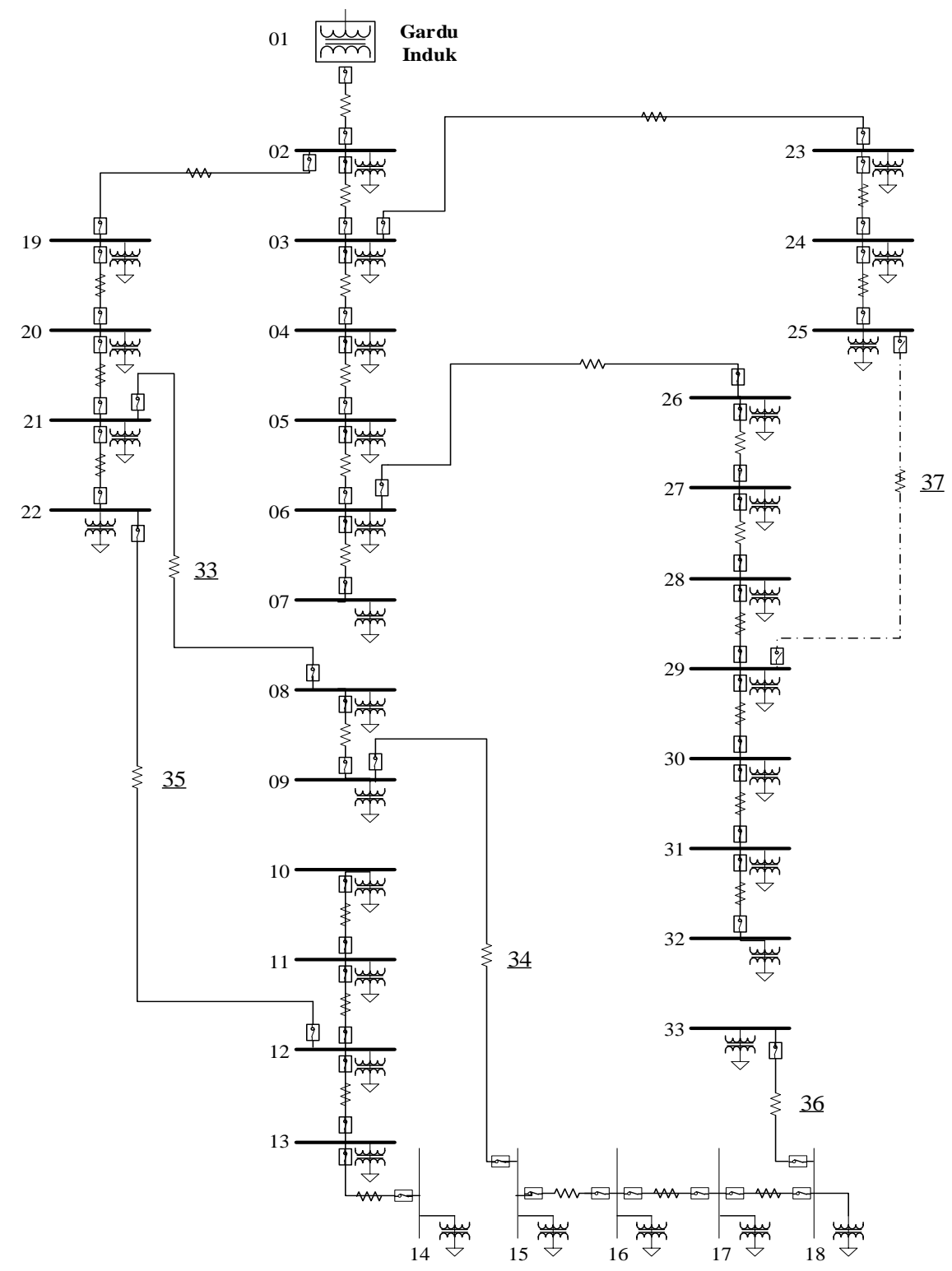

Gambar 3. Single Line Diagram Jaring Distribusi 33-Bus Setelah Rekonfigurasi 
Tabel 4. Tegangan dan Angle Sistem 33-Bus Setelah Rekonfigurasi

\begin{tabular}{|c|c|c|c|c|}
\hline \multirow{2}{*}{$\begin{array}{l}\text { No. } \\
\text { bus }\end{array}$} & \multicolumn{2}{|c|}{ Matlab } & \multicolumn{2}{|c|}{ ETAP } \\
\hline & Tegangan (p.u) & Angle (derajat) & Tegangan (p.u) & Angle (derajat) \\
\hline 1 & 1 & 0 & 1 & 0 \\
\hline 2 & 0,9971 & 0,0145 & 0,9971 & 0,01 \\
\hline 3 & 0,987 & 0,0972 & 0,987 & 0,1 \\
\hline 4 & 0,9825 & 0,1632 & 0,9825 & 0,16 \\
\hline 5 & 0,9782 & 0,2299 & 0,9782 & 0,23 \\
\hline 6 & 0,9673 & 0,2487 & 0,9673 & 0,25 \\
\hline 7 & 0,9667 & 0,2086 & 0,9667 & 0,21 \\
\hline 8 & 0,9626 & $-0,6848$ & 0,9626 & $-0,68$ \\
\hline 9 & 0,9593 & $-0,7364$ & 0,9592 & $-0,74$ \\
\hline 10 & 0,9627 & $-0,6242$ & 0,9627 & $-0,62$ \\
\hline 11 & 0,9628 & $-0,6242$ & 0,9628 & $-0,62$ \\
\hline 12 & 0,9631 & $-0,6264$ & 0,9631 & $-0,63$ \\
\hline 13 & 0,9605 & $-0,6415$ & 0,9605 & $-0,64$ \\
\hline 14 & 0,9597 & $-0,6579$ & 0,9597 & $-0,66$ \\
\hline 15 & 0,9532 & $-0,8928$ & 0,9532 & $-0,89$ \\
\hline 16 & 0,9514 & $-0,9154$ & 0,9514 & $-0,92$ \\
\hline 17 & 0,9485 & $-1,0075$ & 0,9485 & $-1,01$ \\
\hline 18 & 0,9475 & $-1,0185$ & 0,9475 & $-1,02$ \\
\hline 19 & 0,9951 & $-0,0225$ & 0,9951 & $-0,02$ \\
\hline 20 & 0,9782 & $-0,3061$ & 0,9782 & $-0,31$ \\
\hline 21 & 0,9736 & $-0,4252$ & 0,9736 & $-0,43$ \\
\hline 22 & 0,9702 & $-0,5154$ & 0,9702 & $-0,52$ \\
\hline 23 & 0,9834 & 0,0665 & 0,9834 & 0,07 \\
\hline 24 & 0,9768 & $-0,0215$ & 0,9768 & $-0,02$ \\
\hline 25 & 0,9735 & $-0,0648$ & 0,9735 & $-0,06$ \\
\hline 26 & 0,9655 & 0,2859 & 0,9655 & 0,29 \\
\hline 27 & 0,9632 & 0,3388 & 0,9632 & 0,34 \\
\hline 28 & 0,9527 & 0,424 & 0,9527 & 0,42 \\
\hline 29 & 0,9451 & 0,5027 & 0,9451 & 0,5 \\
\hline 30 & 0,9419 & 0,6016 & 0,9419 & 0,6 \\
\hline 31 & 0,9385 & 0,5284 & 0,9385 & 0,53 \\
\hline 32 & 0,9378 & 0,5102 & 0,9378 & 0,51 \\
\hline 33 & 0,9472 & $-1,0225$ & 0,9472 & $-1,02$ \\
\hline
\end{tabular}

Dari hasil analisis aliran daya sistem 33-bus pada kondisi setelah rekonfigurasi didapatkan total kerugian daya aktif sebesar 139,2168 kW dan total kerugian daya reaktif sebesar 102,0619 kVAR serta tegangan minimum terjadi di bus-32 sebesar 0,9378 per unit. Hasil simulasi dengan ETAP setelah dilakukan rekonfigurasi didapatkan total kerugian daya aktif sebesar $140 \mathrm{~kW}$ dan total kerugian daya reaktif sebesar 102 kVAR. Setelah rekonfigurasi dilakukan maka tegangan 
yang didapatkan lebih baik dan kerugian daya yang dihasilkan lebih minimal dari sebelum rekonfigurasi. Tabel 3.2 menunjukkan ada 7 bus yang mempunyai tegangan berada di bawah standar minimum (0,95 p.u.) yakni bus 17 sampai 18 dan bus 29 sampai 33. Ini berarti sebagian besar bus pada kondisi sebelum rekonfigurasi dalam kondisi under voltage telah diperbaiki dengan cara rekonfigurasi jaring sehingga kualitas pelayanan listrik kepada konsumen menjadi lebih baik. Tegangan rata-rata pada kondisi setelah rekonfigurasi menjadi lebih baik, dengan tegangan ratarata sebesar 0,9652 .

\section{KESIMPULAN DAN SARAN}

Berdasarakan hasil simulasi didapat konfigurasi yang paling optimal adalah 7, 9, 14, 32, 37. Nilai tegangan yang dihasilkan setelah rekonfigurasi dan penambahan jaring weakly meshed lebih baik, yaitu rata-rata tegangan sebesar 0,9669 . Kerugian daya yang dihasilkan setelah rekonfigurasi lebih kecil yaitu dari $202,6845 \mathrm{~kW}$ menjadi $126,9307 \mathrm{~kW}$. hasil simulasi pada penelitian ini yang dilaukan pada sistem distribusi radial IEEE 33-bus, menunjukkan bahwa metode simple branch exchange dapat digunakan dan dijadikan sebagai salah satu alternatif solusi dalam melakukan analisis rekonfigurasi jaringan dalam mengurangi rugi-rugi daya pada sistem Distribusi radial. Untuk menentukan menentukan metoda yang paling efektif untuk mengurangi rugi-rugi suatu jaringan kedepannya bisa dilakukan dengan membandingkan dengan metoda rekonfigurasi lainya seperti genetic algorithm.

\section{UCAPAN TERIMAKASIH}

Penelitian ini dapat diseleseaikan atas kontribusi berbagai pihak terutama LPPM STT-PLN. Oleh karena itu penulis meucapkan terima kasih yang telah memberikan dukungan baik moril maupun materil.

\section{DAFTAR PUSTAKA}

[1] Farahani, V., Vahidi, B, and Abyaneh, H.A. (2012). "Reconfiguration and Capacitor Placement Simultaneously for Energy Loss Reduction Based on an Improved Reconfiguration Method". IEEE.

[2] Hao Teng, Jen. (2000) “A Network-Topology-based Three-Phase Load Flow for Distribution Systems".IEEE.

[3] Baran, M.E., Wu, F.F. (1989). "Network reconfiguration in distribution systems for loss reduction and load balancing”, IEEE Trans. Power Deliv., 4, (2), pp. 1401-1407.

[4] Hao Teng, Jen. (2010). "Backward/Forward Sweep-Based Harmonic Analysis Method for Distribution System”s. IEEE.

[5] Nara, K., Shiose, A., Kiagawa, M., Ishihara, T. (1992), "Implementation of genetic algorithm for distribution system loss minimum configuration”, IEEE Trans. Power Syst., 7, (3), pp. 1044-1051. 